\title{
Superplastic Forming of SiAION Ceramics
}

\author{
Shyh-Lung Hwang ${ }^{*}$ and I-Wei Chen*
}

Department of Materials Science and Engineering, University of Michigan, Ann Arbor, Michigan 48109-2136

Superplastic SiAION's of the nominal composition $\mathrm{Y}_{m / 3^{-}}$ $\mathrm{Si}_{12-(m+n)} \mathrm{Al}_{m+n} \mathrm{O}_{n} \mathrm{~N}_{16-n}$ are reported in this study using a transient-phase-forming approach. They encompass the fields of single-phase $\alpha^{\prime}$-SiAlON, single-phase $\beta^{\prime}$-SiAION, and their two-phase mixtures. Excellent formability is obtained at $1550^{\circ} \mathrm{C}$ for the $\beta^{\prime}$ and $\alpha^{\prime}+\beta^{\prime}$ materials, and at $1600^{\circ} \mathrm{C}$ for the $\alpha^{\prime}$ material. Typically in the nonequilibrium state before deformation, these fine-grained materials undergo dramatic phase and microstructure evolutions during superplastic forming. In particular, the stress-biased $\alpha-\mathrm{Si}_{3} \mathrm{~N}_{4} \rightarrow \boldsymbol{\beta}^{\prime}-\mathrm{SiAlON}$ reaction is found to result in elongated and aligned grains with fiber-strengthening effect and excellent formability.

\section{Introduction}

QuPERPLASTICITY is defined phenomenologically as the ability Oof a material to exhibit very large ductility under tensile stretching conditions. ${ }^{1.2}$ Fine-grain superplasticity was broadly reported for yttria-stabilized tetragonal zirconia ceramics. ${ }^{2.3}$ Other ceramic materials that have been recently rendered superplastic include alumina, ${ }^{4}$ mullite, ${ }^{5}$ hydroxyapatite, ${ }^{6}$ and lead titanate. ${ }^{7}$ Superplasticity of silicon nitride was initially reported in a $\mathrm{Si}_{3} \mathrm{~N}_{4} / \mathrm{SiC}$ composite at $1600^{\circ} \mathrm{C}$ at a strain rate of $8 \times 10^{-5}$ $1 / s^{8}$ An equiaxed $\alpha^{\prime}-$ SiAlON, with the aid of a transient liquid, could also be biaxially stretched to a large strain with good surface finish at the same temperature and comparable strain rate $\left(1 \times 10^{-4} \mathrm{l} / \mathrm{s}\right) .^{2} \beta^{\prime}-\mathrm{SiAION}$, with some $15 \mathrm{R}$ polytype and transient liquid, exhibited large tensile ductility at $1550^{\circ} \mathrm{C}$ as well. ${ }^{9}$ In the latter material, the $\beta^{\prime}-S i A l O N$ grew increasingly elongated and became aligned along the tensile direction, causing a pronounced strain hardening and rather high flow stress without premature failure.

The excellent superplasticity of the above silicon nitride materials was obtained at relatively low temperatures. This was necessary in order to prevent rapid grain growth that would otherwise destroy the fine microstructure. In all three cases, some oxynitride glassy phase was also present at the grain boundary. These results suggest that all SiAION materials may be rendered superplastic if formed by low-temperature processing. This should allow the transient liquid, which is formed by the eutectic reaction between oxide additives and nitrides during the fabrication of SiAlON materials, ${ }^{10}$ to remain in the as-formed material to facilitate subsequent superplastic deformation. Since $\alpha-\mathrm{Si}_{3} \mathrm{~N}_{4}$ powders are usually used as the starting material for fabricating SiAlON, the prerequisite of utilizing the transient liquid to enhance superplasticity is that the $\alpha-\mathrm{Si}_{3} \mathrm{~N}_{4}$ to $\alpha^{\prime}$-SiAlON $/ \beta^{\prime}$-SiAlON transformation should not be complete in the as-processed material. (This is possible because densification can precede full phase transformation under suitable processing conditions. ${ }^{11}$ ) Otherwise, most of the additives will

\footnotetext{
D. Wilkinson - contributing editor
}

Manuscript No. 194238. Received September 3, 1993; approved April 26, 1994. Supported by the U.S. National Science Foundation under Grant No. DDM 9024975

* Member, Amcrican Ceramic Society.

${ }^{t}$ Now at Oak Ridge National Laboratory, Oak Ridge, Tennessee 37831. have been incorporated into the SiAlON structure and there will be little or no liquid phase left at the grain boundary for forming purposes.

Guided by the above alloy design concept, we have successfully fabricated several SiAION materials which contain large amounts of unreacted $\alpha-\mathrm{Si}_{3} \mathrm{~N}_{4}$ after fabrication. These materials are inside various phase fields for $\alpha^{\prime}-\mathrm{SiA1ON}, \beta^{\prime}-\mathrm{SiAlON}, \mathrm{AIN}$ polytypoids, and liquid, with reference to the phase behavior and composition diagrams in Fig. 1 . In this report, the deformation behavior and formability of these materials are described and their phases and microstructure are documented. The connection between the transient phase evolutions, microstructure development, and the flow stress and formability is outlined and compared with the alloy design concept.

\section{Experimental Procedure}

\section{(1) Composition}

The compositions of materials investigated here lie on the $\mathrm{Si}_{3} \mathrm{~N}_{4}-\mathrm{Al}_{2} \mathrm{O}_{3}$ :AIN-YN:3AIN plane shown in Fig. 1 and contain, in equilibrium, $\alpha^{\prime}$ - and $\beta^{\prime}-$ SiAION phase assemblages of various proportions. ${ }^{12}$ Since the compositions on the above $\left(\alpha^{\prime}\right)$ plane can be represented by the following formula, $\mathrm{Y}_{m / 3} \mathrm{Si}_{12-(m+n)} \mathrm{Al}_{m+n} \mathrm{O}_{n} \mathrm{~N}_{1(n-n)}$ (i.e., the generic composition for $\alpha^{\prime}$-SiAION), we use $(m, n)$ to designate the composition. For instance, composition 0610 stands for $m=0.6$ and $n=1.0$. Four of these materials are listed in Table I.

In addition to the above materials, we have also investigated a large number of compositions listed in Table II. The prefix P denotes that the material was attrition-milled using porcelain balls (see below on processing), and the composition was not adjusted to compensate for the $\mathrm{SiO}_{2} / \mathrm{Al}_{2} \mathrm{O}_{3}$ pickup during milling. As a result, there is an extra $5-10 \mathrm{wt} \% \mathrm{SiO}_{2} / \mathrm{Al}_{2} \mathrm{O}_{3}$ in addition to the nominal composition indicated. The phase assemblage, microstructure, and the formability of these materials will be compared with those of Table I.

\section{(2) Powder Processing}

The compositions were prepared in 40-g batches from their starting powders $\left[\alpha-\mathrm{Si}_{3} \mathrm{~N}_{4}\right.$ (UBE, E10), AlN (Tokuyama Soda Co., Ltd., Type F), $\mathrm{Al}_{2} \mathrm{O}_{3}$ (Sumitomo Chemical America Inc.

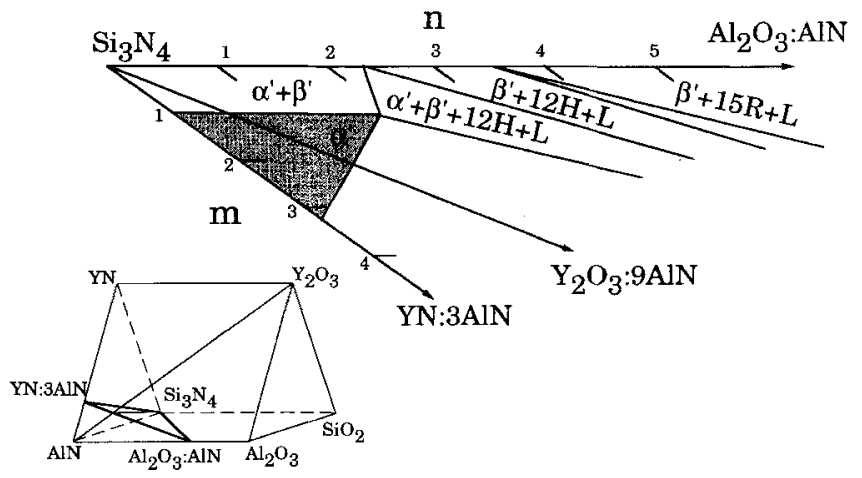

Fig. 1. $\alpha^{\prime}$-plane and the phase regions thereon. The inset at lower left shows a Janecke prism of the $\mathrm{Si}, \mathrm{Al}, \mathrm{Y}-\mathrm{O}, \mathrm{N}$ system that contains the $\alpha$-plane. 
Table I. Phase Assemblages of SiAlON Materials on $\alpha^{\prime}$-Plane

\begin{tabular}{|c|c|c|c|c|}
\hline Materials & Hot-pressed $/ 1550^{\circ} \mathrm{C}$ & Deformed $/ 1550^{\circ} \mathrm{C}$ & Deformed $/ 1600^{\circ} \mathrm{C}$ & Glassy phase \\
\hline 1010 & $44 \% \alpha, 56 \% \alpha^{\prime}$ & $30 \% \alpha, 70 \% \alpha^{\prime}$ & $5 \% \alpha, 90 \% \alpha^{\prime}, 5 \% \beta^{\prime}$ & 5 \\
\hline 0610 & $64 \% \alpha, 27 \% \alpha^{\prime}, 9 \% \beta^{\prime}$ & $32 \% \alpha, 41 \% \alpha^{\prime}, 27 \% \beta^{\prime}$ & $5 \% \alpha, 48 \% \alpha^{\prime}, 47 \% \beta^{\prime}$ & 5 \\
\hline 0625 & $56 \% \alpha, 14 \% \alpha^{\prime}, 30 \% \beta^{\prime}$ & $10 \%\left(\alpha+\alpha^{\prime}\right), 90 \% \beta^{\prime+}$ & & 10 \\
\hline 0650 & $5 \% \alpha,+95 \% \beta^{\prime \dagger}$ & $100 \% \beta^{\prime \prime}$ & & 13 \\
\hline
\end{tabular}

${ }^{+}$Specimen contains some YAG and AIN polytypes $(12 \mathrm{H} / 1.5 \mathrm{R}) .{ }^{+}$The residual $\alpha-\mathrm{Si}_{4} \mathrm{~N}_{3}$ amounts were tentatively indicated as $5 \%$ when the $\alpha-\mathrm{Si}_{3} \mathrm{~N}_{4}$ peaks were very weak in the XRD pitterns.

Table II. Phase Assemblages of SiAlON Materials Containing Excess $\mathrm{SiO}_{2} / \mathrm{Al}_{2} \mathrm{O}_{3}$

\begin{tabular}{lll}
\hline Material & Hot-pressed $/ 1550^{\circ} \mathrm{C}$ & Deformed $/ 1550^{\circ} \mathrm{C}$ \\
\hline P0610 & $40 \% \alpha, 60 \% \beta^{\prime}$ & $100 \% \beta^{\prime}$ \\
P0615 & $39 \% \alpha, 61 \% \beta^{\prime}$ & $100 \% \beta^{\prime}$ \\
P0625 & $36 \% \alpha, 64 \% \beta^{\prime \dagger}$ & $100 \% \beta^{\prime *}$ \\
P0633 & $15 \% \alpha, 85 \% \beta^{\prime \dagger}$ & $100 \% \beta^{\prime \neq}$ \\
P0650 & $100 \% \beta^{\prime \neq}$ & $100 \% \beta^{\prime *}$ \\
P1010 & $40 \% \alpha, 30 \% \alpha^{\prime}, 30 \% \beta^{\prime \dagger}$ & $60 \% \alpha^{\prime}, 40 \% \beta^{\prime \dagger}$ \\
P1015 & $60 \% \alpha, 20 \% \alpha^{\prime}, 20 \% \beta^{\prime \dagger}$ & $57 \% \alpha^{\prime}, 43 \% \beta^{\prime \dagger}$ \\
P1510 & $35 \% \alpha+65 \% \alpha^{\prime \dagger}$ & $90 \% \alpha^{\prime}+10 \% \beta^{\prime \dagger}$ \\
\hline
\end{tabular}

Specimen contains YAG. Specimen contains YAG and AIN polytypes (12H/15R).

AKP50), and $\mathrm{Y}_{2} \mathrm{O}_{3}$ (Aldrich Chemical Co.)]. The powders were attrition-milled in 2-propanol in a Teflon-lined steel jar of $0.7-\mathrm{L}$ size using $500 \mathrm{~g}$ of high-purity alumina milling balls $(2 \mathrm{~mm}$ in diameter) for $2 \mathrm{~h}$ at a speed of $900 \mathrm{rpm}$. The amounts of surface oxides in the starting nitride powders and alumina pickup from the alumina balls were compensated for in the formulation of the initial powder batches. After milling, the powder2-propanol slurry was stirred in a Teflon beaker using a magnetic stirrer and dried under an infrared lamp at about $80^{\circ} \mathrm{C}$.

\section{(3) Hot Pressing}

Dense specimens were obtained by hot-pressing 14-g charges in a graphite resistance furnace using a high-purity graphite die under $1 \mathrm{~atm}$ of nitrogen. The powder was first coldpressed at a load of $27 \mathrm{MPa}$, then loaded into the hot-press. The heating schedule was $25^{\circ} \mathrm{C} / \mathrm{min}$ from room temperature to $1000^{\circ} \mathrm{C}$ followed by $15^{\circ} \mathrm{C} / \mathrm{min}$ to $1550^{\circ} \mathrm{C}$. The holding time at $1550^{\circ} \mathrm{C}$ was $17 \mathrm{~min}$ except material 1010 , which used $30 \mathrm{~min}$. A load of $27 \mathrm{MPa}$ was applied at all times during heating, pressing, and cooling when the temperature exceeded $1000^{\circ} \mathrm{C}$. A detailed study of the hot-pressing behavior of these and other materials has been reported elsewhere. ${ }^{12}$

\section{(4) Mechanical Testing}

Uniaxial compression tests and biaxial punch-stretching tests were performed to evaluate superplastic formability. The specimen dimensions were $3 \mathrm{~mm} \times 3 \mathrm{~mm} \times 6 \mathrm{~mm}$ for compression tests, and $1.2 \mathrm{~mm}$ in thickness by $34 \mathrm{~mm}$ in diameter for punchstretching tests. In compression tests, specimens were placed between two SiC platens with a thin $(0.1 \mathrm{~mm})$ graphite foil in between. For punch-stretching tests, specimens were clamped between two circular graphite dies. A SiC punch with a hemispherical head (12 $\mathrm{mm}$ in diameter) was then used to stretch the specimen into a hemispherical dome at the testing temperature. The details of the setup for punch-stretching tests in our laboratory were given in Ref. 13. (The flange of the specimen was clamped by tightening the dies.) All the tests were performed in a furnace with a tungsten heating element under high-purity flowing nitrogen. The heating rate from room temperature to the testing temperature was $30^{\circ} \mathrm{C} / \mathrm{min}$, and the cooling rate was $200^{\circ} \mathrm{C} / \mathrm{min}$ from the testing temperature to $1000^{\circ} \mathrm{C}$.

\section{(5) Characterization}

Standard characterization using X-ray diffraction (XRD), light microscopy, scanning electron microscopy (SEM), and transmission electron microscopy (TEM) was performed to clarify phase and microstructural evolution before and after deformation. Peak heights in XRD patterns $\left(\alpha^{\prime}(\alpha)_{10 \mathrm{~T} 2}\right.$, $\alpha^{\prime}(\alpha)_{2 \bar{T} T 0}, \beta^{\prime}{ }_{10 T 1}$, and $\left.\beta^{\prime}{ }_{2 T T_{0}}\right)$ were used to calculate the phase contents using the procedure described in Ref. 14. The peak overlap between $\alpha$ and $\alpha^{\prime}$ phases was resolved by a deconvolution procedure which had an uncertainty of about $10 \%$. Pulverized powders were analyzed to eliminate the effect of strong textures caused by hot pressing and subsequent deformation. XRD patterns of the bulk materials were then compared with those of the pulverized powders to assess textures.

\section{Results}

\section{(1) Characterization of As-Hot-Pressed Materials}

At equilibrium, materials $1010,0610,0625$, and 0650 are located in the phase fields of $\alpha^{\prime}, \alpha^{\prime}+\beta^{\prime}, \beta^{\prime}+\alpha^{\prime}+12 H$, and $\beta^{\prime}+15 R+L$, respectively (see Fig. 1). The results of XRD analysis of the as-hot-pressed materials are shown in Table I. All compositions contain unreacted $\alpha-\mathrm{Si}_{3} \mathrm{~N}_{4}$. Its amount generally decreases with the decrease in the $[\mathrm{N}] /[\mathrm{O}]$ ratio in the starting compositions. (The exception of material 1010, which has a lower amount of unreacted $\alpha-\mathrm{Si}_{3} \mathrm{~N}_{4}$ than 0610 and 0625 , is the result of a longer hot-pressing time required to reach full density.) It has been demonstrated that the rate of $\alpha-\mathrm{Si}_{3} \mathrm{~N}_{4}$ to $\alpha^{\prime}$ or $\beta^{\prime}$-SiAlON transformation decreases rapidly with $[\mathrm{N}] /[\mathrm{O}]$, because of the viscosity dependence on this ratio. ${ }^{15}$ This is in agreement with our observations. We also found that $\mathrm{Y}_{3} \mathrm{Al}_{5} \mathrm{O}_{12}$ (YAG) formed in materials 0625 and 0650 at a temperature as low as $1300^{\circ} \mathrm{C}$ during initial heating, probably by a solid-state reaction between $\mathrm{Y}_{2} \mathrm{O}_{3}$ and $\mathrm{Al}_{2} \mathrm{O}_{3}$. AlN polytypoids, $12 \mathrm{H}$ and $15 \mathrm{R}$, were also found in these materials after hot pressing. The larger amount of unreacted $\alpha-\mathrm{Si}_{3} \mathrm{~N}_{4}$ in all except material 0650 and the relatively low $\beta^{\prime}$-SiAION content in materials 0610 and 0625 indicate that phase equilibria have not been reached after hot pressing.

SEM micrographs of fracture surfaces of these materials are shown in Fig. 2. The grain sizes in materials 1010, 0610, and 0625 are similar, in the range of about $0.2 \mu \mathrm{m}$, smaller than that $(0.4 \mu \mathrm{m})$ of material 0650 . The distribution of the glassy phase can be better seen on a polished section, as shown in Fig. 3 . Large glass pockets, which appear as light areas, due to the presence of yttrium, are visible in materials 0625 and 0650 but not in materials 1010 and 0610 . Using a point counting method, we estimated the amount of glassy phase in materials 0650 and 0625 to be 13 and 10 vol\%, respectively. The amount of glassy phase in materials 1010 and 0610 was also roughly estimated from TEM micrographs, which gave values less than 5 vol\% on average. These values are listed in Table I for reference. 

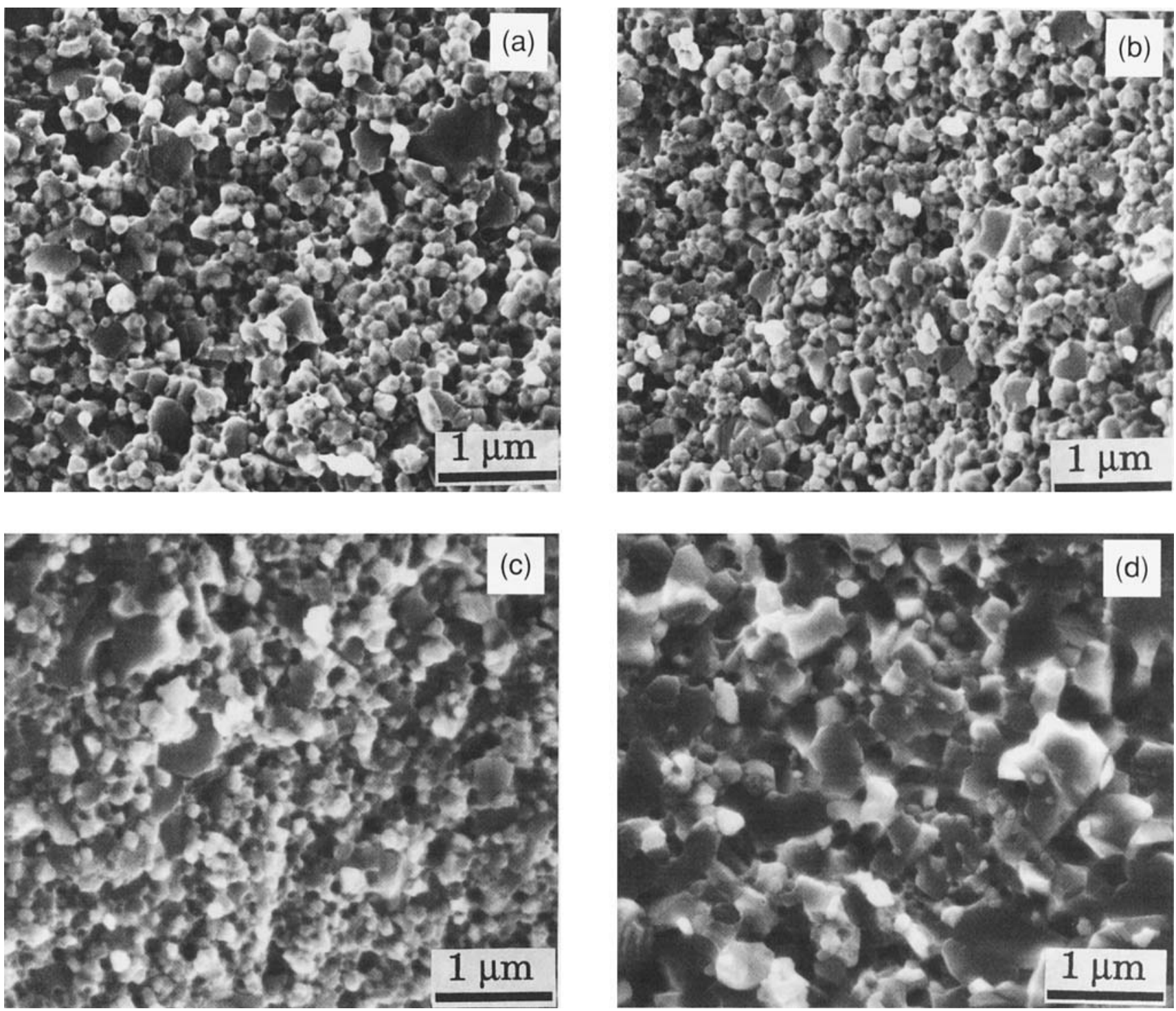

Fig. 2. SEM micrographs of materials (a) 1010, (b) 0610, (c) 0625, and (d) 0650 after hot pressing.

The materials 1010,0610 , and 0625 have similar grain morphology after hot pressing. Figure 4(a) is a TEM micrograph of material 1010. This microstructure consists of rounded grains with a grain size in the range of 0.1 to $0.5 \mu \mathrm{m}$, with the smaller grains usually surrounded by an intergranular glassy phase, which appears in dark contrast under bright-field imaging conditions due to the presence of yttrium. The grain morphologies of materials 0610 and 0625 are also similar. In contrast, the microstructure of material 0650 consists of grains having an average grain size of about $0.4 \mu \mathrm{m}$, some of them faceted, as shown in Fig. 4(b). Elongated grains, however, are rarely seen in any of these specimens. The effect of excess $\mathrm{SiO}_{2} / \mathrm{Al}_{2} \mathrm{O}_{3}$ beyond the composition on the $\alpha^{\prime}$ plane is seen in Table II. For comparable nominal compositions, the phase assemblage of the as-hot-pressed materials in Table II contains less unreacted $\alpha-\mathrm{Si}_{3} \mathrm{~N}_{4}$, less $\alpha^{\prime}-\mathrm{SiAlON}$, and more $\beta^{\prime}-\mathrm{SiAlON}$ than those in Table I. Microstructural examination found that these $\mathrm{SiO}_{2} /$ $\mathrm{Al}_{2} \mathrm{O}_{3}$ rich materials contain more glassy phase. $\mathrm{A}$ fine-grained microstructure, however, is still maintained in all cases.

\section{(2) Compression Tests}

Compression tests were performed at $1550^{\circ} \mathrm{C}$ at strain rates ranging from $1 \times 10^{-4}$ to $1 \times 10^{-3} \mathrm{l} / \mathrm{s}$. A single specimen was used for each strain rate. A typical set of stress-strain curves is shown in Fig. 5 for material 0610 . At higher strain rates, a constant flow stress is maintained over a large range of strain, indi- cating steady-state deformation. At lower strain rates, strain hardening is relatively more pronounced. For these experiments, we have compared the flow stress at $500 \mathrm{~s}$ after deformation. As shown in Fig. 6, these plots exhibit two regimes: in the lower strain rate range, the slope is close to 1 , indicating Newtonian flow; at higher strain rates, the slope increases to around 2 , indicating shear thickening. ${ }^{16}$ (The division of two regimes for material 0625 is not as distinct because of data scatter, but it is still consistent with the above description.) This transition occurs at a characteristic stress around $20 \mathrm{MPa}$, which is the same as we reported for several similar materials previously. ${ }^{16}$ This is found to be universal for all of the fine-grained SiAlON materials that we investigated thus far. For example, Fig. 7 plots the results of six other materials which all fall in the compositional range bounded by materials 1010 and 0650 . This indicates that the four materials reported here are indeed representative of other materials on the $\alpha^{\prime}$-plane.

\section{(3) Punch-Stretching Test}

Clamped punch-stretching tests were conducted at a constant crosshead speed of $0.2 \mathrm{~mm} / \mathrm{min}$ until failure. The above speed corresponds to an average strain rate of $2 \times 10^{-4} \mathrm{I} / \mathrm{s}$. A set of load-displacement curves for the four SiAION materials tested at $1550^{\circ} \mathrm{C}$ is shown in Fig. 8. The vertical dashed line indicates that the travel equals the punch radius $(6 \mathrm{~mm})$ beyond which a 

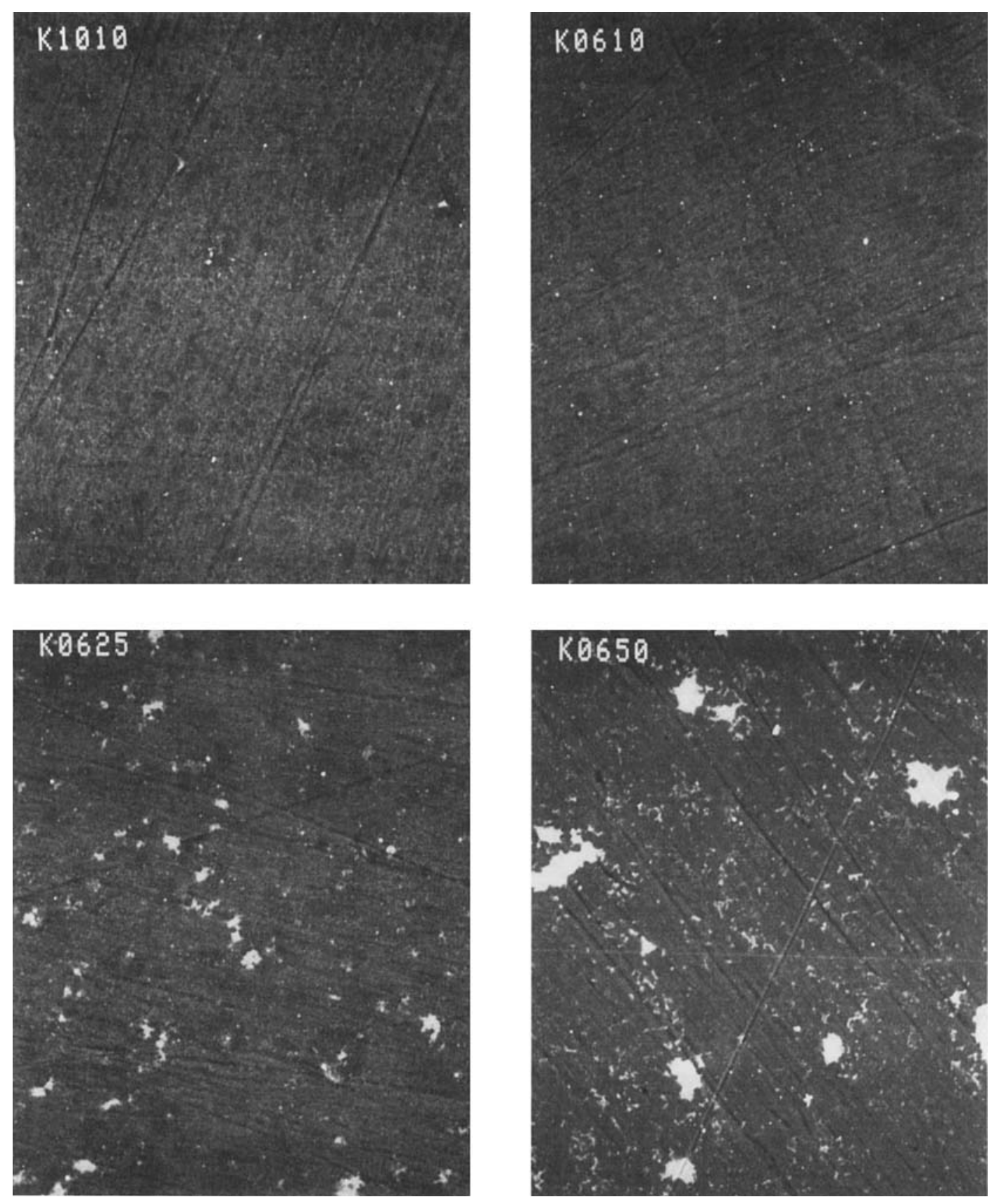

Fig. 3. SEM micrographs of polished surfaces showing glassy phase distibutions.

hemispherical dome is already achieved. At the strain rate used, punch-stretching lies below the Newtonian/shear thickening transition described above. The forming loads vary in the same order as that of the compressive flow stress in different materials: $0610 \approx 1010>0625>0650$. The formability is generally large with the exception of material 1010. Since materials 1010 and 0610 have similar flow stress but very different formability at $1550^{\circ} \mathrm{C}$, punch-stretching tests were also conducted at $1600^{\circ} \mathrm{C}$ for these two materials. These results are included in Fig. 8. For both materials, the forming load at $1600^{\circ} \mathrm{C}$ is about $30 \%$ lower than that at $1550^{\circ} \mathrm{C}$, and the formability improves significantly, particularly for material 1010 .

Results of punch-stretching tests performed for the $\mathrm{SiO}_{2} /$ $\mathrm{Al}_{2} \mathrm{O}_{3}$ rich materials listed in Table II are shown in Fig. 9. (For some of these materials, tests were terminated when the punch displacement reached $10 \mathrm{~mm}$.) For the same nominal compositions, the forming loads are smaller than those shown in Fig. 8, with the exception of material P0650, which has a similar forming load to material 0650 . Once again, the formability is uniformly good except material P1510. Note also that material P1010 has a much greater formability than material 1010 .

\section{(4) Surface and Fractography}

After punch-stretching, materials 1010 and 0610 had a better surface finish than materials 0625 and 0650 . The surfaces of the latter were covered by a thin layer of silicates, as shown in Fig. 10(a), which was believed to be the result of thermal decomposition of the glassy phase with a high oxygen content. In contrast, the surfaces of materials 1010 and 0610 were very shiny and had no such products. The above difference is consistent with the different amount of glassy phase listed in Table 1. However, some cavities about $2 \mu \mathrm{m}$ in diameter were formed on materials 1010 and 0610 during the testing, as shown in Fig. 10(b). No linkage of these cavities was observed, though, until the failure strain. 

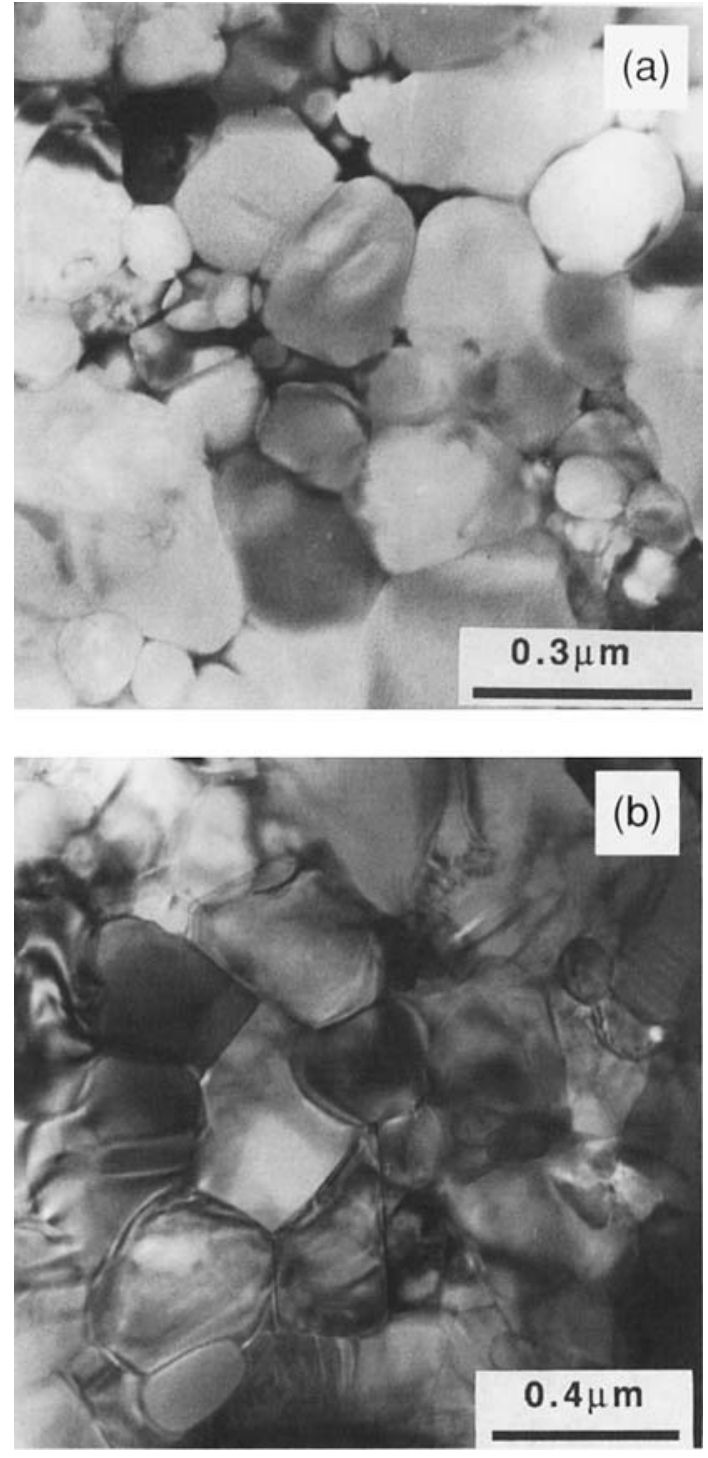

Fig. 4. TEM micrographs showing grain morphology in materials (a) 1010 and (b) 0650 after hot pressing.

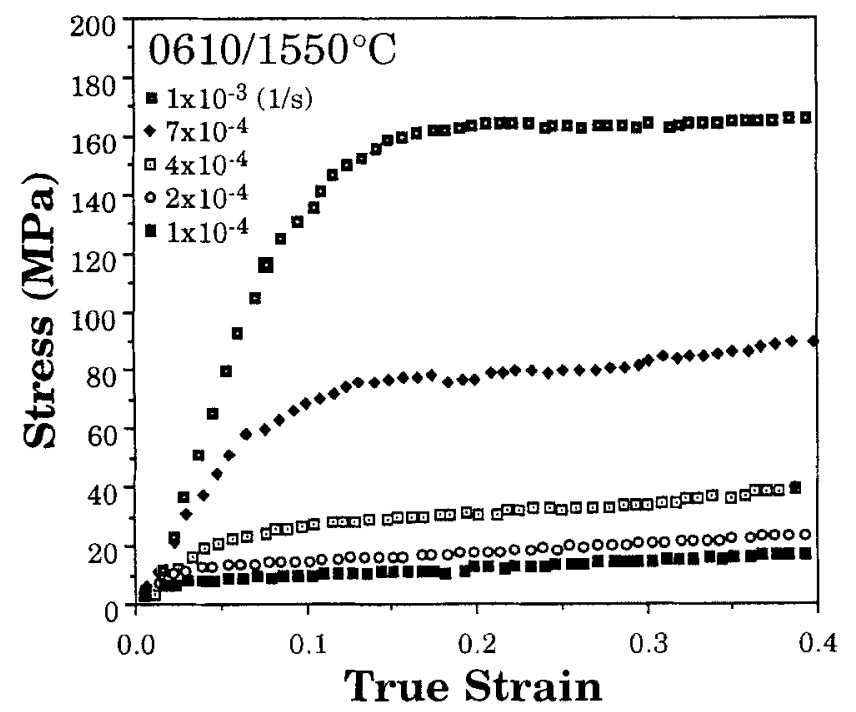

Fig. 5. Flow stress vs true strain curves in compression for material 0610 at $1550^{\circ} \mathrm{C}$.

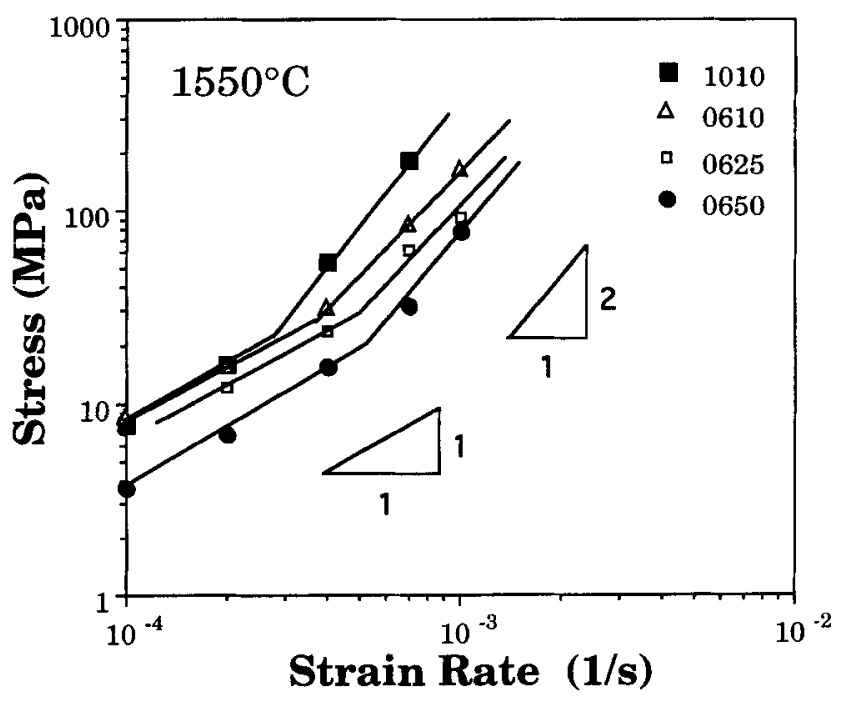

Fig. 6. Flow stress vs strain rate in compression for materiais 1010 , 0610,0625 , and 0650 at $1550^{\circ} \mathrm{C}$.

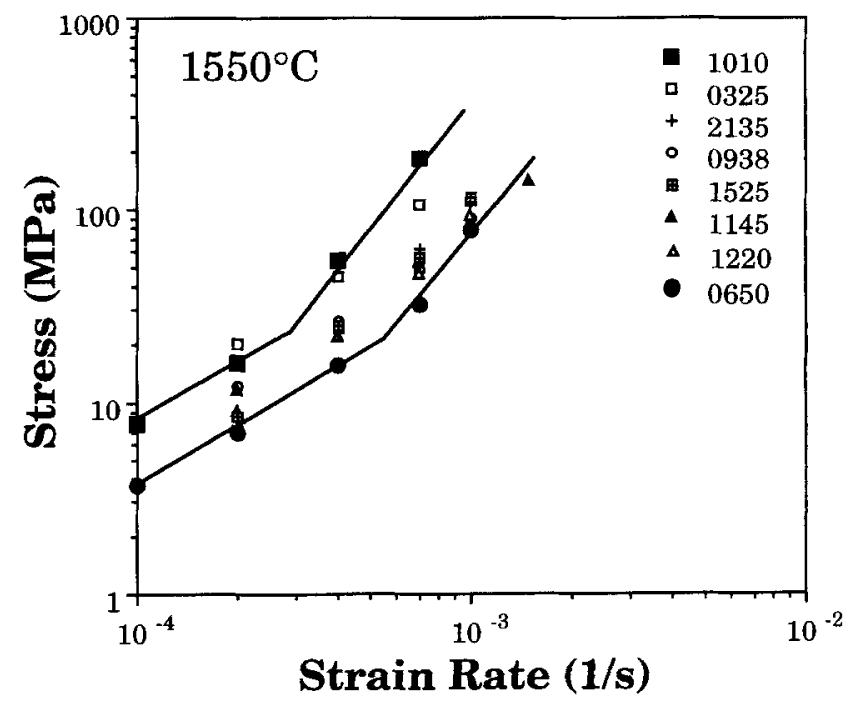

Fig. 7. Flow stress vs strain rate in compression for SiAlON materials on $\alpha^{\prime}$-plane $\left(1550^{\circ} \mathrm{C}\right)$. Lines are shown for materials 1010 and 0650 that border the compositional range.

Failures of materials 1010,0610 , and 0625 occurred abruptly by the formation of a single long crack which rapidly propagated across the whole hemispherical dome, resulting in a sudden load drop. In most cases, the long crack did not extend to the pole but remained $1-2 \mathrm{~mm}$ away from it. For material 0650 , which had the lowest forming load, a gradual decrease in the load accompanied the progression of fracture. Multiple cracks of smaller sizes could be observed on the dome. Many of these cracks have a " $\lambda$ " shape, with two cracks emanating from the same origin, which is characteristic of damage under a biaxial stress state. Similar phenomena were observed in materials processed with porcelain balls; materials of the lowest forming load, P0633 and P0650, showed multiple cracks with a gradual decrease in load, while others experienced a sudden load drop with only one long crack in each failed specimen.

The thickness of the dome was measured at various locations from the pole after the test. In all cases there is a region near the pole of $2 \mathrm{~mm}$ in radius which has a uniform thickness. The "friction hill" effect previously observed in superplastic zirconia, which gives a larger thickness at the pole, has never been seen here. ${ }^{13}$ This is indicative of the good lubrication afforded 


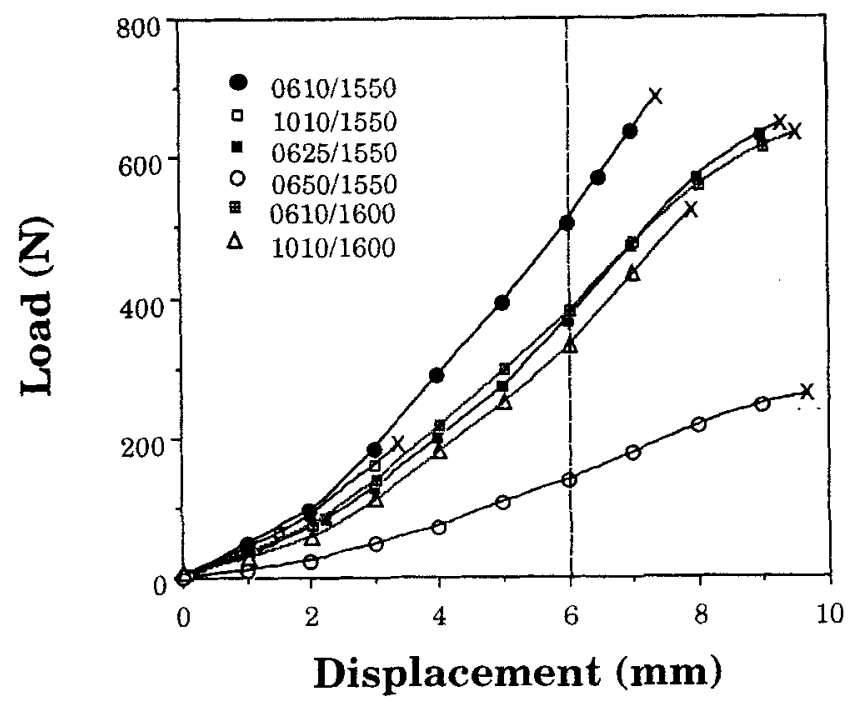

Fig. 8. Forming load vs punch displacement for materials 0610 , 1010,0625 , and 0650 (punch velocity $=0.2 \mathrm{~mm} / \mathrm{min}$ ). Fracture indicated by cross at the end of the curve.

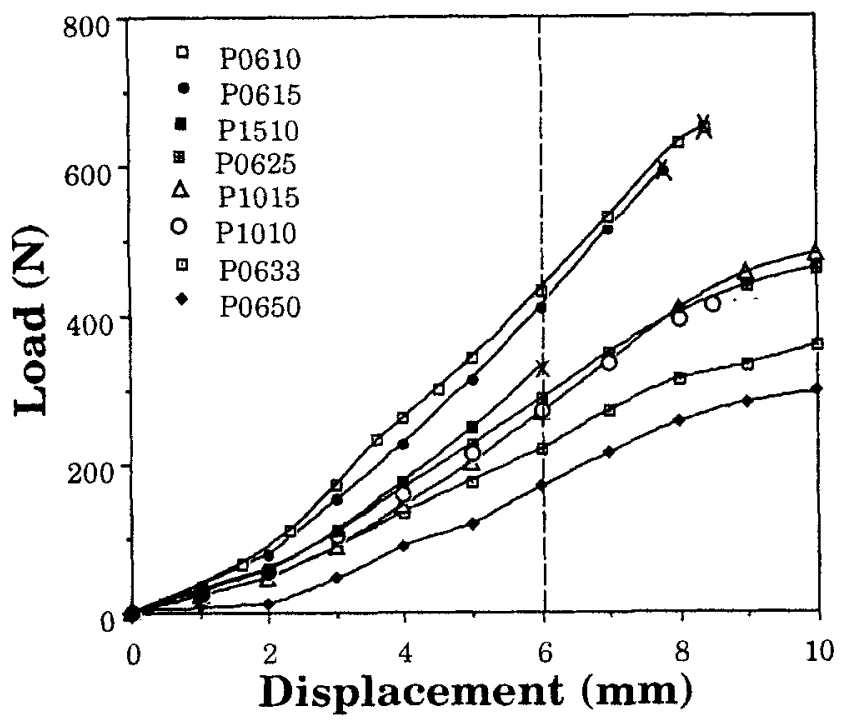

Fig. 9. Forming load vs punch displacement for SiAlON materials containing excess $\mathrm{SiO}_{2} / \mathrm{Al}_{2} \mathrm{O}_{3}$ (punch velocity $=0.2 \mathrm{~mm} / \mathrm{min}, T=$ $1550^{\circ} \mathrm{C}$ ). Fracture indicated by cross at the end of the curve.

by the graphite foil placed between the SiC punch and the SiAlON specimen, and perhaps by the glassy phase of SiAION itself.

\section{(5) Deformation Microstructure}

(A) XRD Analysis: Phase assemblage and deformation texture of the punch-stretched specimens were examined by XRD in both the as-deformed and the pulverized states. The deformed state refers to the pole region of the punch-stretched specimens examined in the "top view" direction. The pulverized state refers to the same but crushed into powders. Such patterns are displayed in Fig. 11. The data on phase assemblage estimated for pulverized samples are also summarized in Tables I and II. In all cases, the amount of unreacted $\alpha-\mathrm{Si}_{3} \mathrm{~N}_{4}$ decreases, while that of $\alpha^{\prime} / \beta^{\prime}$-SiAlON increases after deformation. At $1600^{\circ} \mathrm{C}$, the reaction rate is much faster than that at $1550^{\circ} \mathrm{C}$. In particular, the amount of $\beta^{\prime}-\mathrm{SiAlON}$ tends to increase. Comparing materials with and without excess $\mathrm{SiO}_{2} /$ $\mathrm{Al}_{2} \mathrm{O}_{3}$, we found the ones with the excess oxides transformed
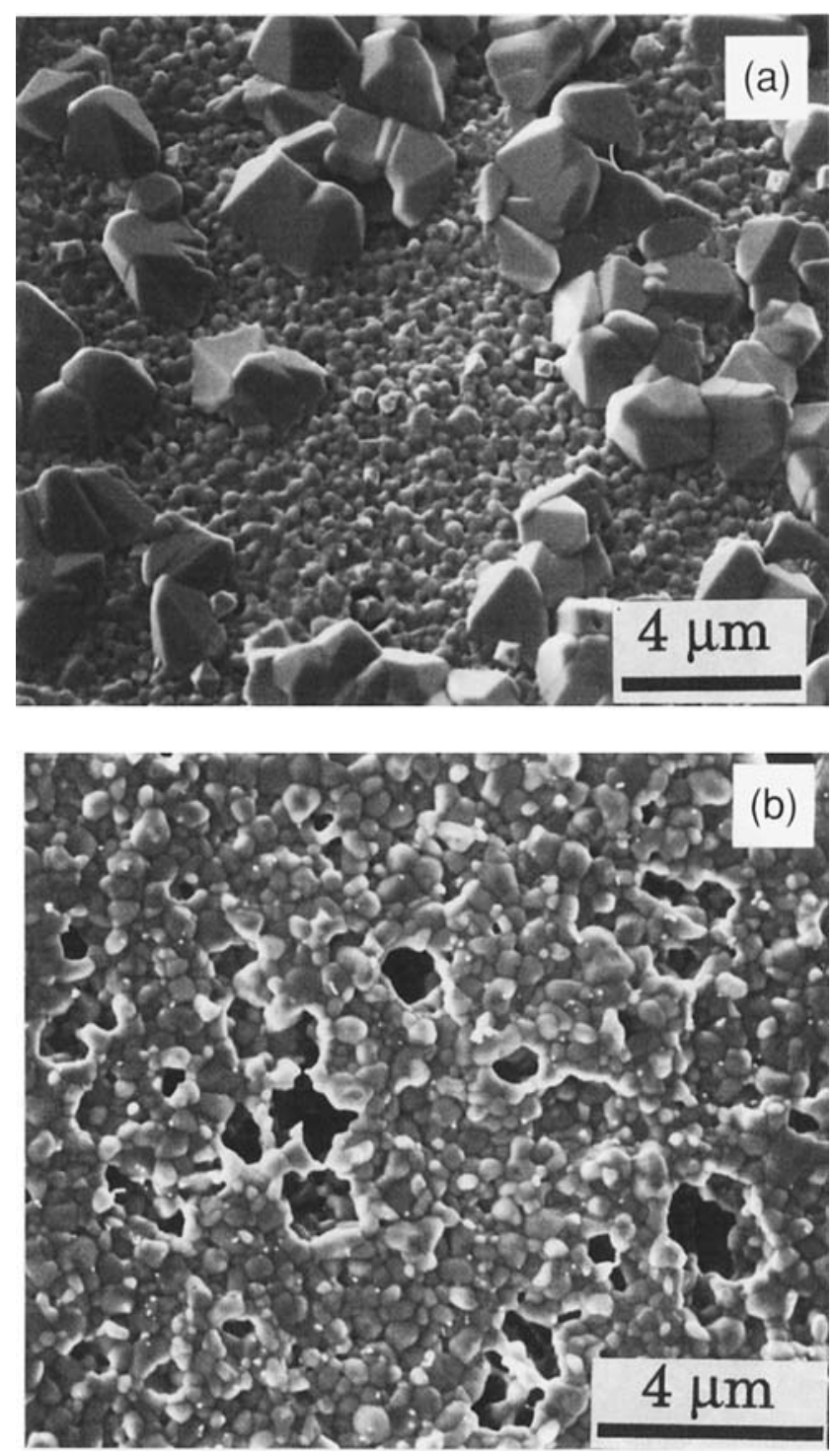

Fig. 10. Light micrographs showing (a) decomposition layer on material 0625 and (b) cavities on material 0610 after punch-stretching at $1550^{\circ} \mathrm{C}$ for $30 \mathrm{~min}$.

more. Indeed, none of the deformed specimens with excess oxides have unreacted $\alpha-\mathrm{Si}_{3} \mathrm{~N}_{4}$ left.

Comparing the peak height ratios of XRD patterns in the pulverized and as-deformed state, we notice strong deformation textures, especially for $\beta^{\prime}-$ SiAlON. In material 0610 and 0625 , the peak height ratio of $\beta_{2 \overline{1} \mathrm{~T} 0}^{\prime} / \beta^{\prime}{ }_{1011}$ is $\sim 17$ and $\sim 8$, respectively, in the as-deformed state, while it is close to 1 in the pulverized state. This texture indicates that the [0001] direction of $\beta^{\prime}$-grains lies on the biaxial stretching plane. Although some texture was inherited from hot pressing, these strong textures of $\beta^{\prime}$-SiAION grains were mostly enhanced by deformation. (The $\beta^{\prime}{ }_{2 T T 0} / \beta^{\prime}{ }_{10 \pi 1}$ peak height ratio of the as-hot-pressed and annealed $0610 / 0625$ specimens was only around 2 .) The deformation effect on the texture of $\beta^{\prime}$-SiAlON grains in material 0650 is much weaker. The peak height ratio of $\beta^{\prime}{ }_{2 \overline{\mathrm{T} T} 0} / \beta^{\prime}{ }_{10 \mathrm{~T} 1}$ is $\sim 2$, compared with the ratio of 1.15 observed for the as-hotpressed and annealed material. The $\alpha^{\prime}$-SiAlON also appeared to be slightly textured, having a stronger $\alpha^{\prime}{ }_{2 T 10}$ than $\alpha^{\prime}{ }_{10 T 2}$ in materials 1010 and 0610 in the deformed state. However, this texture must have already formed during hot pressing, because the peak height ratio of $\alpha^{\prime}{ }_{2 \pi T \alpha} / \alpha^{\prime}{ }_{10 \bar{T} 2}$ is found to be close to 1.5 for materials 1010 and 0610 after hot pressing at $1550^{\circ} \mathrm{C}$ and annealing at $1600^{\circ} \mathrm{C}$ for $1 \mathrm{~h}$. (For brevity, some of the XRD patterns of these materials are not shown here.) 
(a) 1010

(b) 0610

(c) 0625

(d) ) 0650
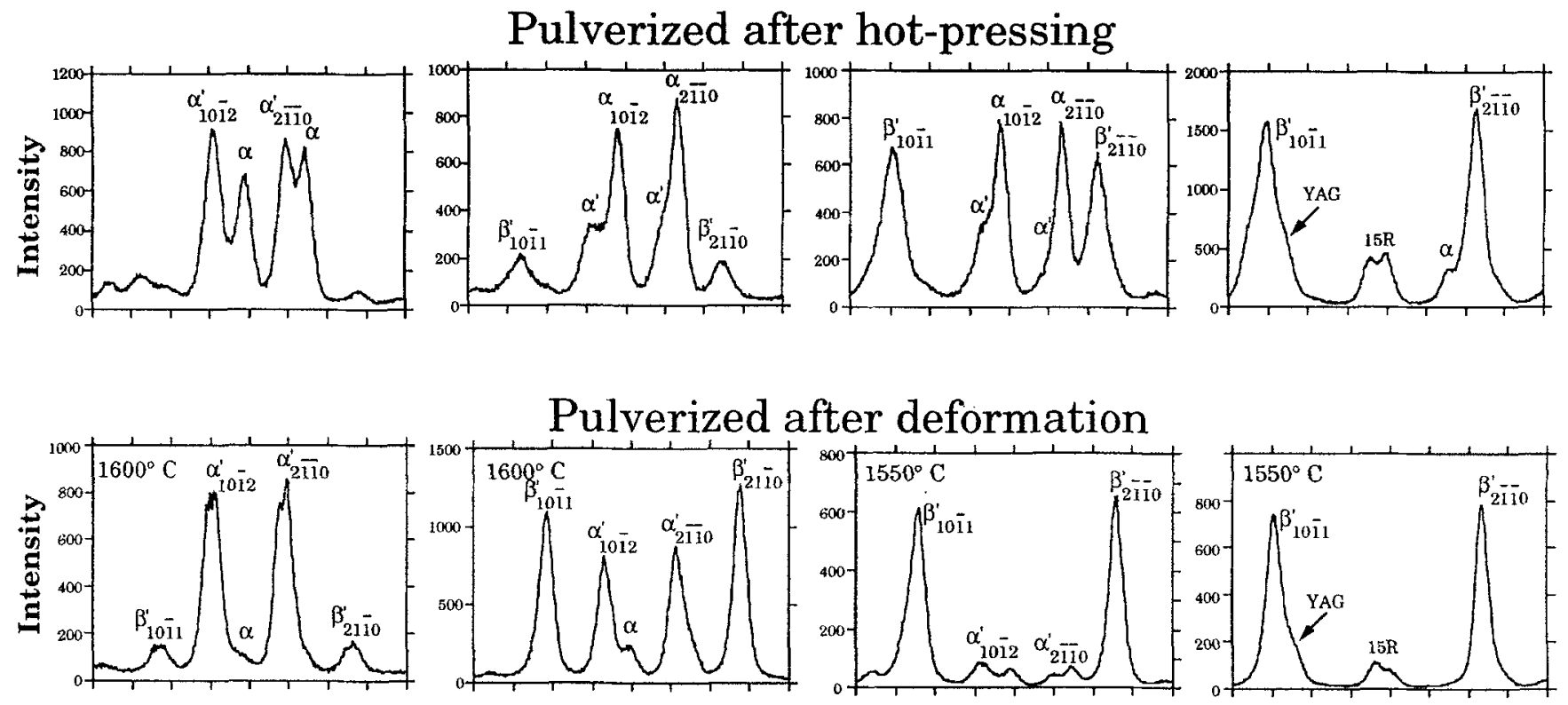

As deformed

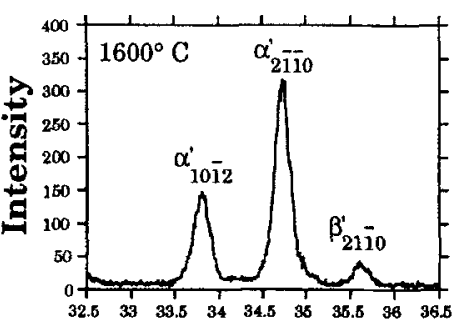

$2 \theta$

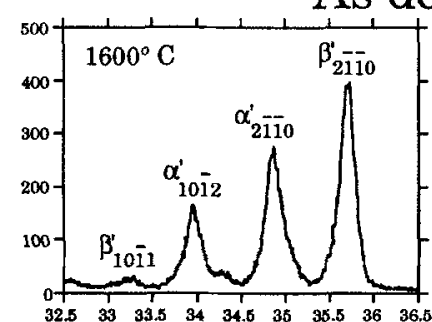

$2 \theta$

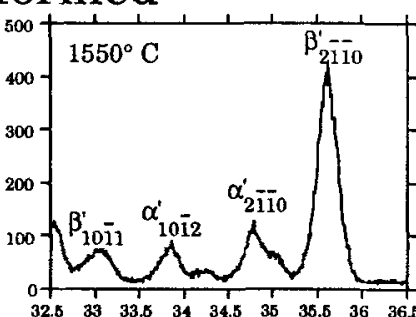

$2 \theta$

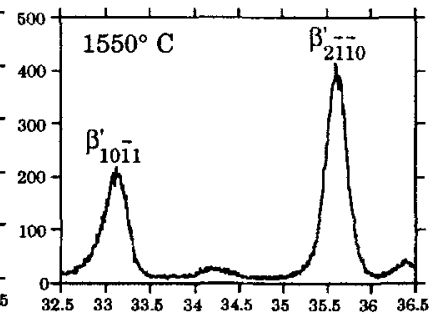

$2 \theta$

Fig. 11. XRD patterns for materials (a) 1010, (b) 0610, (c) 0625, and (d) 0650 after hot pressing and pulverization (first row), after punch-stretching and pulverization (second row), and after punch-stretching in the bulk form (third row).

Lastly, to determine whether punch-stretching has enhanced the $\alpha$-to- $\beta^{\prime}$ or $\alpha$-to- $\alpha^{\prime}$ transformation, we have compared the XRD patterns of the pulverized samples of the pole and the flange regions of the punch-stretched specimens. The phase assemblages of these two regions were found to be the same, indicating that the deformation effect is limited to texture enhancement only.

(B) SEM: Selected SEM micrographs of surfaces fractured after the punch-stretching tests are given in Fig. 12. After testing at $1550^{\circ} \mathrm{C}$, materials 1010 and 0610 have a very small grain size (not shown), $\sim 0.3 \mu \mathrm{m}$, compared to that before deformation, $\sim 0.2 \mu \mathrm{m}$. At $1600^{\circ} \mathrm{C}$, the deformed microstructure of the same materials (Figs. 12(a,b)) consists of much larger grains, around $0.6 \mu \mathrm{m}$, and some elongated grains attributable to $\beta^{\prime}-$ SiAION which can be seen even in material 1010 . Materials 0625 and 0650 , which both contain a large amount of $\beta^{\prime}$-SiAlON after punch-stretching at $1550^{\circ} \mathrm{C}$, have much larger grain sizes. Clearly, the stability of microstructure and the morphology are dependent on the starting phase assemblage and the temperature.

(C) TEM: The microstructural content under various deformation and annealing conditions can be clearly revealed by TEM. The TEM specimen for the punch-stretched material was taken from the pole of the hemispherical dome with the thin foil parallel to the shell surface. The microstructure of material 0610 after punch-stretching at $1600^{\circ} \mathrm{C}$ is given in Fig. 13(a), compared with that of an undeformed material from the flange of the same specimen shown in Fig. 13(b). Recall that in this material the deformed portion has a very strong $\beta^{\prime}$-texture.
Although the initial microstructure of the as-hot-pressed material contains mainly equiaxed grains and no elongated $\beta^{\prime}-\mathrm{SiAlON}$ grains, the deformed microstructure, however, contains many elongated $\beta^{\prime}$-SiAlON grains, with high aspect ratio, aligned on the biaxial stretching plane. This appearance is mostly due to the deformation texture since the microstructure of the annealed but undeformed material also contains mostly equiaxed grains, with only relatively few randomly oriented, elongated $\beta^{\prime}$-SiAlON grains. Thus, deformation promotes the growth of elongated $\beta^{\prime}-$ SiAION grains and affects the alignment of the rodlike $\beta^{\prime}-$ SiAION grains. The behavior is similar to that reported for material 0650 after the tension test. ${ }^{9}$

A similar study of material 1010 deformed at $1600^{\circ} \mathrm{C}$ was performed. Note that in this material the deformed portion contains essentially no $\beta^{\prime}$-SiAlON and only $\alpha^{\prime}$-SiAlON. As shown in Fig. 14(a), the microstructure contains only equiaxed grains with a core-shell structure, which is a result of the epitaxial growth of $\alpha^{\prime}$-SiAlON on the $\alpha-\mathrm{Si}_{3} \mathrm{~N}_{4}$ starting powders as was discussed elsewhere. ${ }^{17}$ For this material, there is no apparent difference between the deformed and the annealed microstructures (not shown), in either the grain size or grain morphology.

Turning to material 0650 , which contains only $\beta^{\prime}-$ SiAlON and no $\alpha^{\prime}$-SiAION, some deformation effect has again been observed but it is not as strong as that in material 0610 . We found the elongated $\beta^{\prime}$-SiAION grains still align along the biaxial stretching plane, but the aspect ratio is much smaller than material 0610, as shown in Fig. 14(b). The difference between the deformed and annealed microstructures (not shown) is not as large as in material 0610 either. Note that in this $100 \%$ 

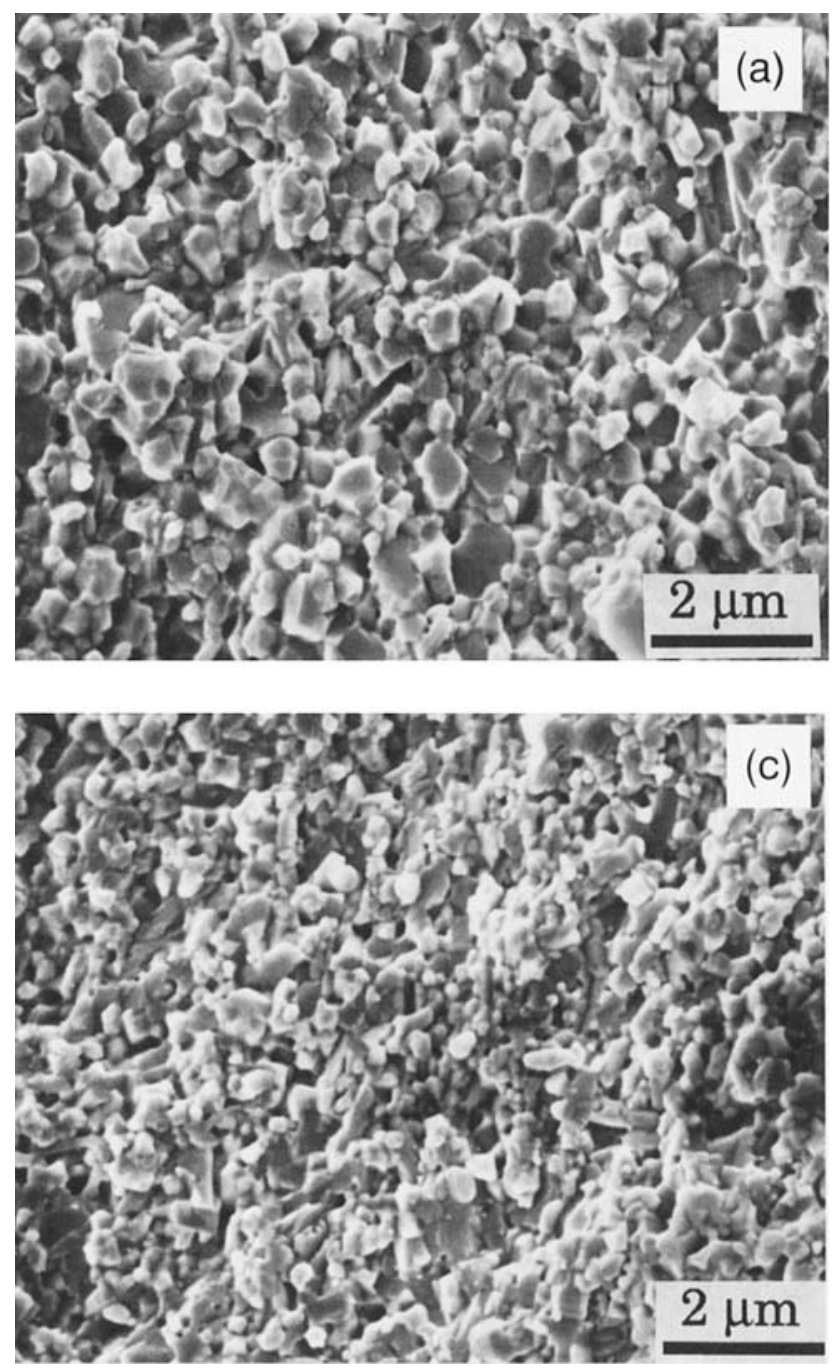
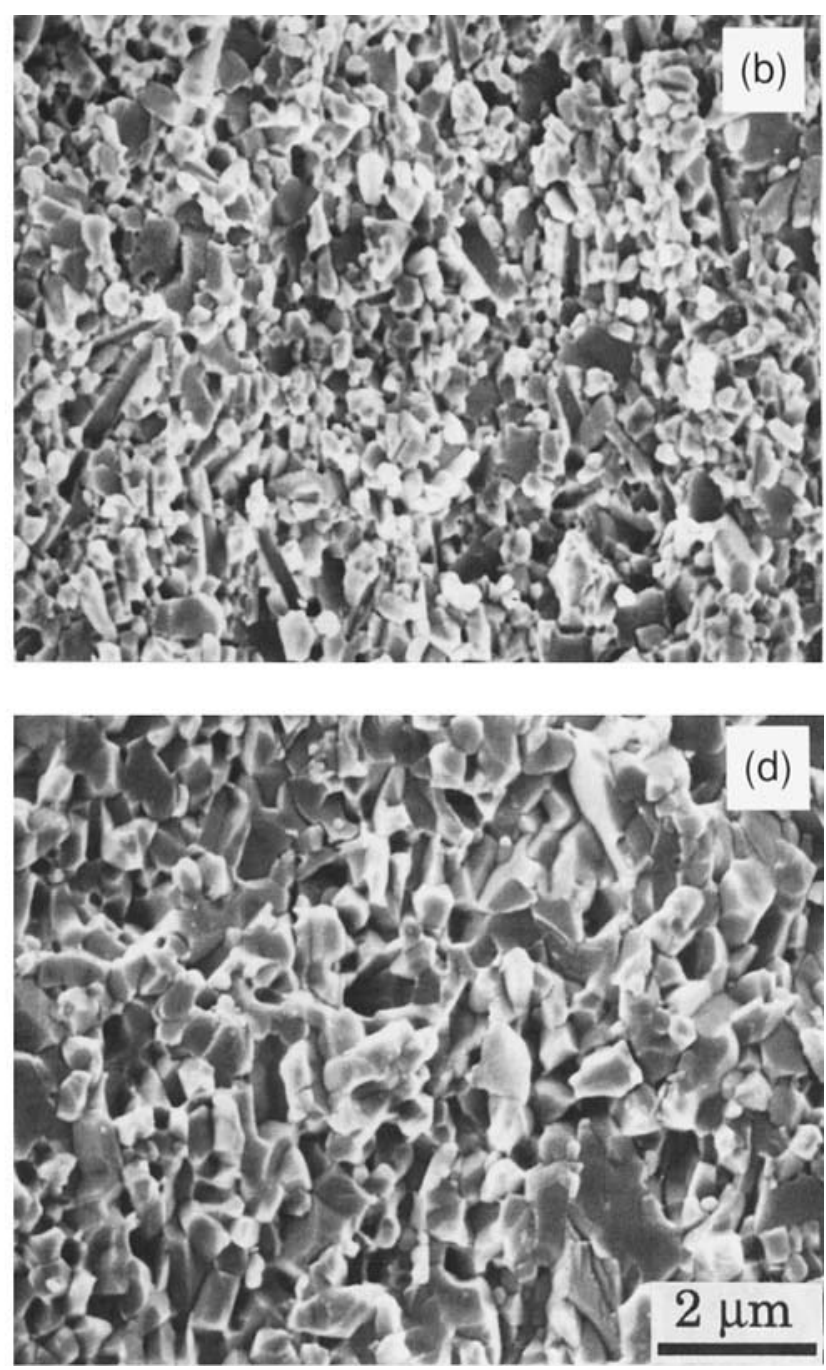

Fig. 12. SEM micrograph of surfaces fractured after punch-stretching for (a) material 1010 at $1600^{\circ} \mathrm{C}$, (b) material 0610 at $1600^{\circ} \mathrm{C},(\mathrm{c})$ material 0625 at $1550^{\circ} \mathrm{C}$, and (d) material 0650 at $1550^{\circ} \mathrm{C}$.

$\beta^{\prime}-$ SiAlON material, with only about 15 vol\% grain boundary glassy phase, the elongated grains appear interlocked.

Finally, microcracks have been searched for in the TEM examination but never detected on these biaxially stretched materials. Neither could dislocation activity be found in the deformed materials. (Evidence for interface dislocations and some dislocations that formed due to thermal mismatch between phases has been observed, however, as detailed elsewhere. ${ }^{18}$ ) This result supports that deformation occurs via viscous flow.

\section{Discussion}

\section{(1) Phase and Microstructure Evolutions}

The phases and microstructure of the as-hot-pressed materials undergo further changes during annealing and deformation. According to our results, the phase evolutions are not accelerated by deformation, but the microstructural changes are. At $1550^{\circ} \mathrm{C}$, the approach toward equilibrium is not complete in all except material 0650 , even after punch-stretching to a full dome. At $1600^{\circ} \mathrm{C}$, equilibrium is mostly attained after similar deformation. The kinetics (judged by the amount of the unreacted $\alpha-\mathrm{Si}_{3} \mathrm{~N}_{4}$ ) increases when $n$ increases (and when $m$ decreases) in the formulation which is generally consistent with the expectation of glass viscosity that decreases with [O]/[N] ratio in these systems. This is further supported by the observation that all materials with excess $\mathrm{SiO}_{2} / \mathrm{Al}_{2} \mathrm{O}_{3}$ reach phase equilibrium after punch-stretching at $1550^{\circ} \mathrm{C}$.
Some larger grains exist in all of the $\alpha^{\prime}$-SiAlON materials, like material 1010 . This is more noticeable in the deformed state when they reach a size of $1 \mu \mathrm{m}$, in a background of grains of $0.3 \mu \mathrm{m}$. These large grains could have caused local stress concentrations leading to premature fracture. The growth of $\alpha^{\prime}-\mathrm{SiAlON}$ by a core-shell mechanism has been detailed elsewhere. ${ }^{18}$ Some examples can be seen in Figs. 13(b) and 14(a). Such observations imply that several $\alpha^{\prime}$-grains grow around an $\alpha-\mathrm{Si}_{3} \mathrm{~N}_{4}$ seed crystal. Thus, the large $\alpha^{\prime}$-grains are probably the direct result of some large $\alpha-\mathrm{Si}_{3} \mathrm{~N}_{4}$ particles in the starting powders.

$\beta^{\prime}$-SiAlON grains which are elongated can be easily identified, as in the micrographs of the deformed materials. However, it should be noted that many $\beta^{\prime}$-SiAlON grains are nearly equiaxed and do not reveal themselves in these micrographs even though they figure prominently in XRD. This is especially true in the as-hot-pressed material, e.g., 0625. This implies that $\beta^{\prime}$-SiAlON grains are initially equiaxed but become elongated later during deformation because of the fast growth in the axial direction.

The most important effect of deformation on microstructural development lies in the morphology and texture of $\beta^{\prime}$-SiAlON. Deformation promotes the growth of elongated $\beta^{\prime}-$ SiAION grains in the direction of maximum principal stress and affects the alignment of the resultant rodlike grains in the same direction. The extent of $\beta^{\prime}$-texture depends strongly on the amount of unreacted $\alpha-\mathrm{Si}_{3} \mathrm{~N}_{4}$ in the as-hot-pressed materials. The clear evidence for this comes from the three materials 0610,0625 , 

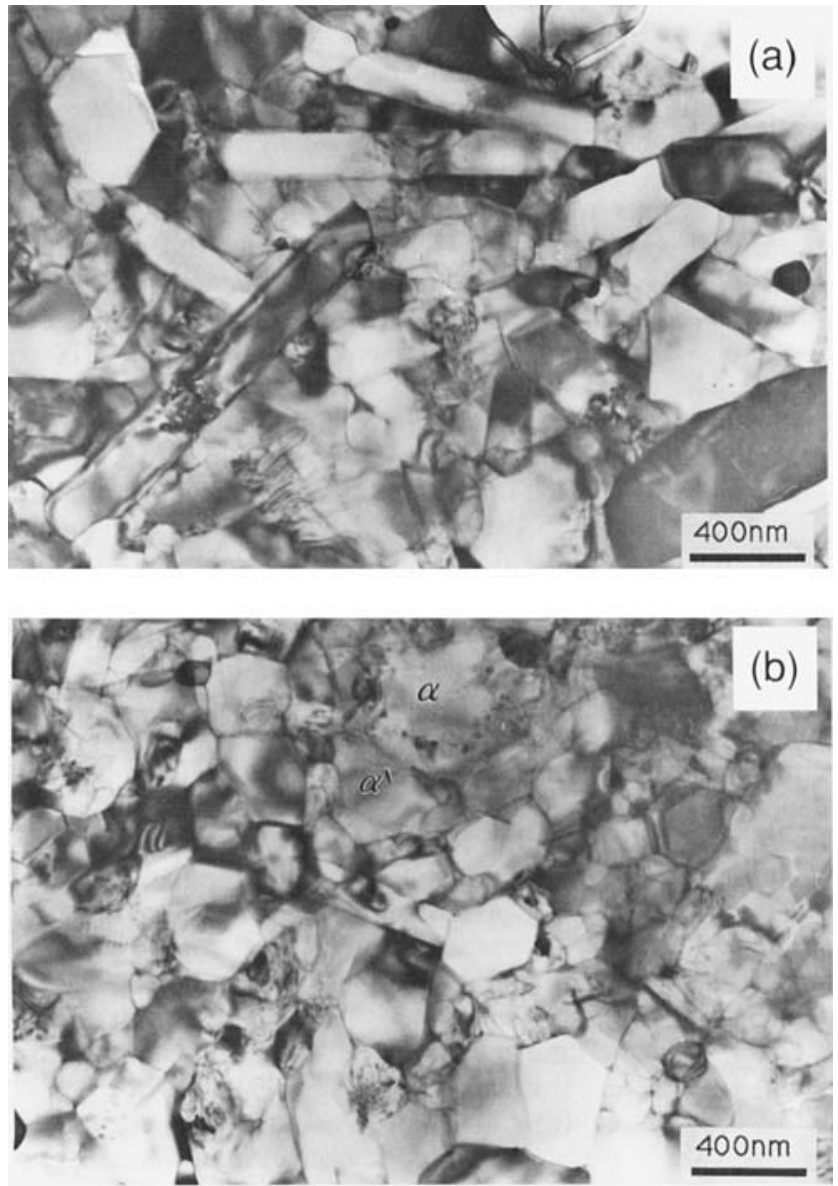

Fig. 13. TEM micrographs of material 0610 after (a) punch-stretching at $1600^{\circ} \mathrm{C}$ and $(\mathrm{b})$ annealing at $1600^{\circ} \mathrm{C}$. The core-shell microstructure showing an $\alpha^{\prime}$-grain surrounding an $\alpha$-center region is indicated in (b).

and 0650 that were punch-stretched at $1550^{\circ} \mathrm{C}$. The amount of $\alpha-\mathrm{Si}_{3} \mathrm{~N}_{4}$ prior to deformation is $64 \%, 56 \%$, and $<5 \%$, respectively, from Table I, which correlates with the resulting peak height ratio of $\beta_{2 T{ }_{2} /}^{\prime} / \beta^{\prime}{ }_{10 T 1}, 17,8$, and 2 , respectively. Thus, an applied stress field can cause very strong $\beta^{\prime}$-texture if it is accompanied by $\alpha-\mathrm{Si}_{3} \mathrm{~N}_{4}$ to $\beta^{\prime}$-SiAION transformation.

The kinematic for texture formation in terms of grain rotation has been modeled by $\mathrm{Wu}$ and Chen. ${ }^{9}$ Their model predicts a unique strain dependence that was successfully tested on a material similar to 0650 which has no residual $\alpha-\mathrm{Si}_{3} \mathrm{~N}_{4}$. The additional effect of $\alpha$ - to $\beta^{\prime}$-SiAlON transformation on $\beta^{\prime}$-texture, on the other hand, arises if some residual $\alpha-\mathrm{Si}_{3} \mathrm{~N}_{4}$ remains in the starting material. This effect probably originates from the stress bias for preferential deposition onto the $\beta^{\prime}$-SiAION grains. When the [0001] directions are aligned in the biaxial tensile direction, the applied stress provides a bias for the dissolution (of $\alpha-\mathrm{Si}_{3} \mathrm{~N}_{4}$ ) and the precipitation (of $\beta^{\prime}$-SiAlON) processes that proceed actively in these reacting materials. Since the main driving force of this reaction and material deposition process is that of $\alpha \rightarrow \beta^{\prime}$ transformation which is much larger than the mechanical bias itself, very substantial texturing effects can result even with a small bias stress. The textures obtained in this case are not expected to be explicitly dependent on the strain but are mostly dictated by the amount of time-dependent $\alpha$ - to $\beta^{\prime}$-SiAlON transformation during deformation.

To compare the two mechanisms for texture formation, we have measured the textures formed in the compression test in material 0650 at several strain rates. Note that this material contains $<5 \% \quad \alpha-\mathrm{Si}_{3} \mathrm{~N}_{4}$ before deformation; therefore, only the
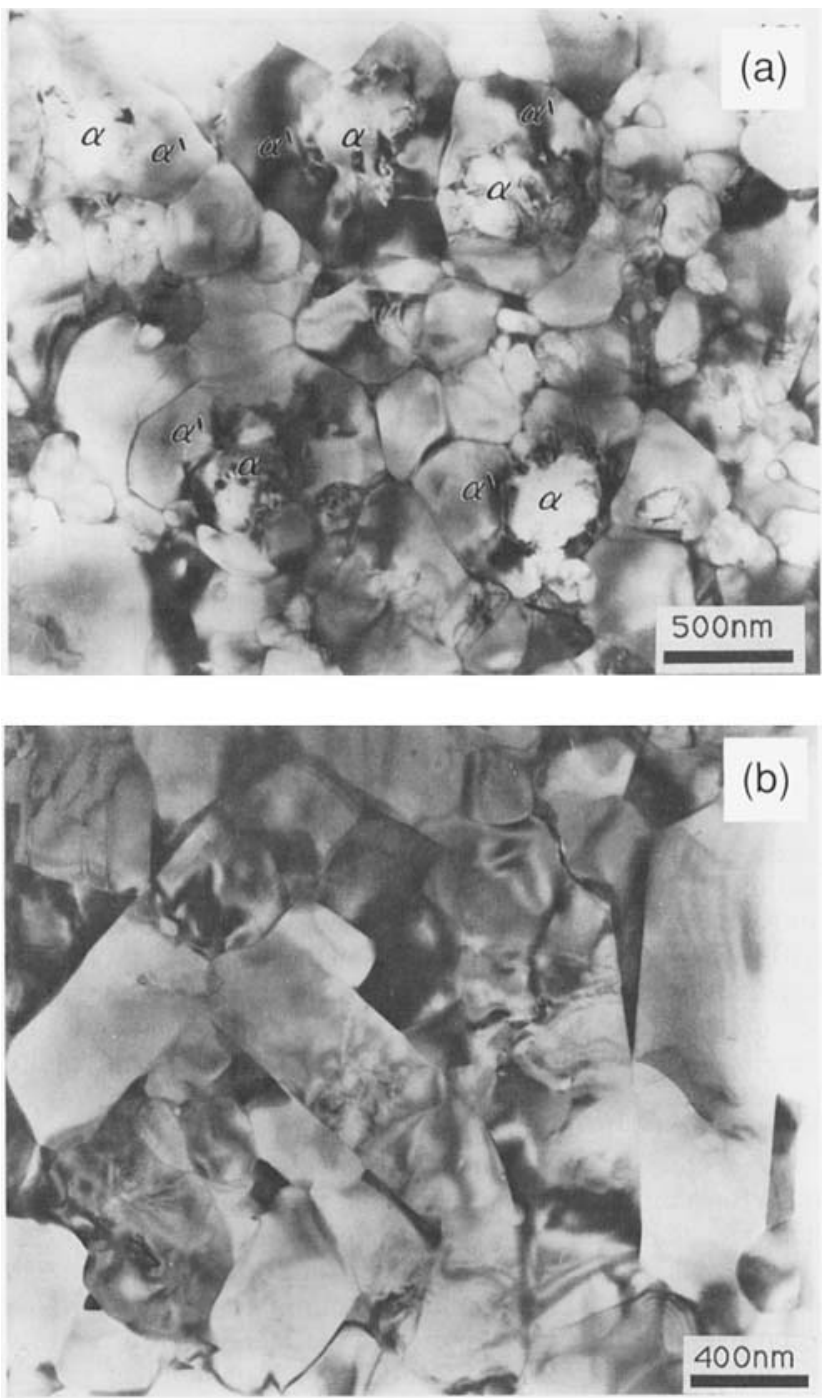

Fig. 14. TEM micrographs of (a) material 1010 after punch-stretching at $1600^{\circ} \mathrm{C}$ and (b) material 0650 after punch-stretching at $1550^{\circ} \mathrm{C}$ The core-shell microstructure showing $\alpha^{\prime}$-grains surrounding $\alpha$-center regions is indicated in (a).

grain rotation mechanism, and not the transformation mechanism, could operate. As shown in Fig. 15, the textures developed in compression of material 0650 were indeed dependent on the deformation strains only. (It is independent of strain rates, which are in the range of $1 \times 10^{-4}$ to $1 \times 10^{-3} \mathrm{l} / \mathrm{s}$.) The textures of two punch-stretched materials, 0610 and 0625 , which contain unreacted $\alpha-\mathrm{Si}_{3} \mathrm{~N}_{4}$, are much larger than material 0650 at a comparable strain. Thus, while the two mechanisms are probably additive, the one related to phase transformation can certainly dominate, as in the case of material 0610 .

\section{(2) Flow Stress and Forming Load}

From the results plotted in Figs. 5-8, the flow stress/forming load of various SiAlON materials is found to qualitatively vary in a systematic way, reflecting the effect of composition. First, for the same nominal composition, the material containing excess $\mathrm{SiO}_{2} / \mathrm{Al}_{2} \mathrm{O}_{3}$ has a lower flow stress/forming load. Second, the flow stress/forming load decreases with increasing $n$ and decreasing $m$. The above two observations are consistent with the notion that melt viscosity, which increases with [N]/ [O] ratio, scales with flow stress. This implies the central role played by the liquid phase in SiAlON superplasticity.

The additional influence of microstructures, however, is also evident. First, the flow stress/forming load experiences a minimum when the amounts of equilibrium $\alpha^{\prime}$ and $\beta^{\prime}$ phases are 


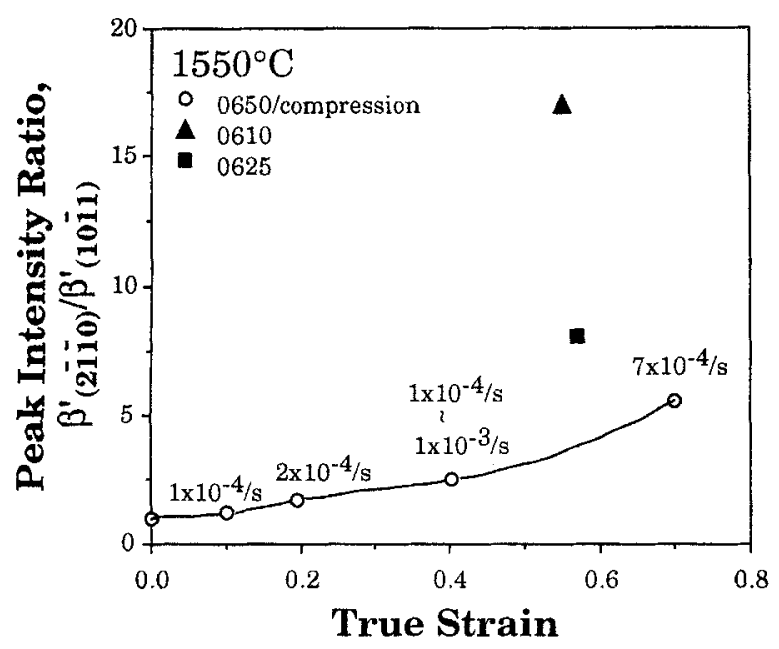

Fig. 15. XRD peak height ratio vs true strain for material 0650 (in compression) and materials 0610 and 0625 (both in punch-stretching). The higher ratio is correlated to more $\alpha \rightarrow \beta^{\prime}$ transformation.

nearly equal. For example, for the same $n=1.0$, the forming load of P1010 $\left(60 \% \alpha^{\prime}, 40 \% \beta^{\prime}\right)$ is lower than those of P0610 $\left(100 \% \beta^{\prime}\right)$ and P1510 $\left(90 \% \alpha^{\prime}\right)$. Likewise, the forming load of $\mathrm{P} 1015\left(57 \% \alpha^{\prime}, 43 \% \beta^{\prime}\right)$ is lower than that of P0615 (100\% $\left.\beta^{\prime}\right)$ despite a lower $m$ value in the latter. (In the above, the phase assemblage refers to the one measured after deformation which more nearly approaches the equilibrium condition.) This feature is well known for superplastic metals and alloys, ${ }^{1,19}$ but is observed for the first time for superplastic ceramics.

The second important influence of microstructure on flow stress/forming load can be seen from the temperature dependence. The activation energy of the flow stress of silicon nitride materials which have reached phase equilibrium is around 650 $\mathrm{kJ} / \mathrm{mol}$, according to other studies in our laboratory. This value is comparable to the one reported in the literature $(760 \mathrm{~kJ} / \mathrm{mol}$ in Ref. 20 and $750 \mathrm{~kJ} / \mathrm{mol}$ in Ref. 21 , both obtained at around $1000^{\circ} \mathrm{C}$ ) and can be mainly attributed to the softening of glass. Thus, a very steep temperature dependence might have been expected for the flow stress/forming load, and it would predict that the forming load at $1600^{\circ} \mathrm{C}$ to be only $32 \%$ of that at $1550^{\circ} \mathrm{C}$. According to Fig. 8, however, the forming load of materials 1010 and 0610 at $1600^{\circ} \mathrm{C}$ is about $70 \%$ of that at $1550^{\circ} \mathrm{C}$. This indicates that the softening effect of glass at $1600^{\circ} \mathrm{C}$ is substantially counteracted by other microstructural effects. One such effect is grain coarsening, which is slow at $1550^{\circ} \mathrm{C}$ but much faster at $1600^{\circ} \mathrm{C}$. In addition, since the phase transformation from $\alpha$ to $\alpha^{\prime} / \beta^{\prime}$ is much faster at $1600^{\circ} \mathrm{C}$, the amount of transient liquid and its $\mathrm{Al} / \mathrm{Y}$ content (and hence fluidity) should decrease rapidly, again causing an increase of flow stress. This aspect once more underlines the nonequilibrium nature of the superplastic SiAION materials investigated in this study.

\section{(3) Formability of SiAlONs}

Punch-stretching formability of superplastic ceramics usually improves as the flow stress/forming load decreases. This trend is mostly obeyed in the present set of materials, although the correlation between formability and forming load is not as strong as documented for other ceramics. ${ }^{2}$ The highest forming load for successful punch-stretching in our experiments was around $500-600 \mathrm{~N}$. Using the model developed by $\mathrm{Wu}$ and Chen, ${ }^{13}$ the maximum stress near the pole is estimated to be around $15-25 \mathrm{MPa}$ under the above load. This value is similar to the magnitude for the shear-thickening transition and seems to represent the maximum stress the grain boundary glass can sustain between two adjoining grains.

As the temperature increases, the glass viscosity decreases somewhat but the microstructure coarsens rapidly. Eventually, we expect the flow stress to increase again and local stress concentrations around the large grains to become significant at higher temperatures. This limits the upper forming temperature. In the other limit of lower temperatures, the flow stress increases rapidly because of viscosity increase, which also limits the formability. Indeed, it has been demonstrated that for a material similar to 0650 , the maximum tensile elongation is obtained between $1500^{\circ}$ and $1600^{\circ} \mathrm{C}$. 9 Thus, the window for forming temperature is quite narrow for this family of SiAlON materials.

Among the materials investigated, only materials 1010 and $\mathrm{P} 1510$, both tested at $1550^{\circ} \mathrm{C}$, have relatively low formability. It is notable that both materials have an essentially $\alpha / \alpha^{\prime}$ phase assemblage, while all other materials contain a considerable amount of $\beta^{\prime}$-SiAION. Indeed, the somewhat better formability of $\mathrm{P} 1510$ compared to 1010 is correlated with a small amount of $\beta^{\prime}$-SiAION (10\%) that does exist in P1510 after deformation, and the much improved formability of 1010 at $1600^{\circ} \mathrm{C}$ is also accompanied by the formation of $5 \% \beta^{\prime}$ during deformation. (Of course, in both cases, the forming load also decreases at $1600^{\circ} \mathrm{C}$, which is partly responsible for the improved formability as already discussed above.) This correlation of poor formability with the absence of $\beta^{\prime}-$ SiAION is rather remarkable. It cannot be due to the relatively low strength of $\alpha^{\prime}$-SiAION either (as often evidenced by room-temperature fracture experiments ${ }^{22}$ ) because the failure stress relevant in punch-stretching is only about $20 \mathrm{MPa}$, much lower than the strength of any grain.

We believe the role of $\beta^{\prime}$-SiAlON in formability lies in its tendency to form elongated grains and to align on the biaxial stretching plane. These grains can produce a fiber-strengthening effect and retard the fracture process. ${ }^{9,23}$ While this beneficial effect is most significant in materials containing a large fraction of $\beta^{\prime}$-SiAlON (and especially if it is formed in situ during deformation for $\alpha^{\prime}-\mathrm{Si}_{3} \mathrm{~N}_{4}$ and transient liquid), the effect is still substantial at a lower fraction. In fact, it is well known that a relatively small amount of whiskers, e.g., 10\%, is capable of increasing the fracture toughness substantially in whiskerreinforced ceramics. ${ }^{24}$

\section{Conclusion}

(1) All the SiAlON ceramics on the $\alpha^{\prime}$-plane have been demonstrated to be superplastic by punch-stretching tests. These materials have a very fine-grained microstructure and are typically in a nonequilibrium state before deformation.

(2) The formability of these SiAION ceramics depends on the deformation temperature, forming velocity, and phase assemblage. $\beta^{\prime}$-SiAlON and $\left(\alpha^{\prime}+\beta^{\prime}\right)$-SiAlON have better formability than $\alpha^{\prime}$-SiAlON.

(3) The better formability in the $\beta^{\prime}$ and $\left(\alpha^{\prime}+\beta^{\prime}\right)$-SiAlON is suggested to result from the fiber-strengthening effect of the elongated and aligned $\beta^{\prime}$-SiAION. Such grains can form during deformation by stress-biased preferential deposition when a large amount of unreacted $\alpha-\mathrm{Si}_{3} \mathrm{~N}_{4}$ is present before deformation.

(4) The flow stress of these superplastic SiAlON's is dependent on the viscosity of the intergranular glass. It experiences a minimum in the equal-fraction two-phase region similar to that found in superplastic metallic alloys.

\section{References}

'J. W. Edington, K. N. Melton, and C. P. Culter, "Superplasticity," Prog Mater. Sci., 21 [2] 61-170 (1976).

"I-W. Chen and L. A. Xue, "Development of Superplastic Structural Ceramics," J. Am. Ceram. Soc., 73 [9] 2585-609 (1990).

${ }^{3}$ F. Wakai, S. Sakaguchi, and Y. Matsuno, "Superplasticity of Ytria-Stabilized Tetragonal Zirconia Polycrystal," Adv. Ceram. Mater., 1 [3] 259-63 (1986).

${ }^{4}$ L. A. Xue, X. Wu, and I-W. Chen, "Superplastic Alumina Ceramics with Grain Growth Inhibitors," J. Am. Ceram. Soc., 74 [4] 842-45 (1991).

'L. A. Xue and I-W. Chen, "Fabrication of Mullite Body Using Superplastic Transient Phases," J. Am. Ceram. Soc., 75 [5] 1185-91 (1992). 
${ }^{6} \mathrm{~F}$. Wakai, Y. Kodama, S. Sakaguchi, and T. Nonami, "Superplasticity of Hot Isostatically Pressed Hydroxyapatite," I. Am. Ceram. Soc, 73, 457-60 (1990).

${ }^{7}$ F. Wakai, Y. Koduma, N. Murayama, S. Sakaguchi, T. Rouxel, S. Sato, and T-O. Nonami, "Superplasticity of Functional Ceramics"; pp. 205-14 in Superplasticity in Advanced Materials. Edited by S. Hori, M. Toticane, and N. Furushiro. Japanese Society for Research on Superplasticity, Osaka, Japan, 1991.

${ }^{8}$ F. Wakai, Y. Kodama, S. Sakaguchi, N. Murayama, K. Izaki, and K. Nihara "A Superplastic Covalent Crystal Composites," Nature (London), 344, 421-23 $(1990)$.

${ }^{7 X}$. Wu and I-W. Chen, "Exaggerated Texture and Grain Growth of a Superplastic SiAlON," J. Am. Ceram. Soc., 75 [10] 2733-41 (1992).

"'K. H. Jack, "The Characterization of $\alpha$ '-SiAION and the $\alpha-\beta$ Relationships in SiAIONs and Silicon Nitride"; pp. 45-60 in Progress in Nitrogen Ceramics. Martinus Nijhoff Publishers, Boston, MA, 1983.

${ }^{1 "} \mathrm{C}$. M. Hwang and T. Y. Tien, "Densification and Phase Transformation During Sintering of Silicon Nitride Ceramics"; pp. 1034-39 in Sintering "87, Proceedings of the 4th International Symposium on the Science and Technology of Sintering, Vol. 2. Edited by S. Somiya, M. Shimada, M. Yoshimura, and R. Watanabe. Elsevier Publishers, London, U.K., 1988.

${ }^{12}$ S.-L. Hwang and I-W. Chen, "Reaction Hot Pressing of $\alpha$ '- and $\beta$ '-SiAlON Ceramics,"I. Am. Ceram. Soc., 77 [1] 165-71 (1994).

${ }^{1 .} \mathrm{X}$. Wu and I-W. Chen, "Superplastic Bulging of Fine-Grained Zirconia," J. Am. Ceram. Soc., 73 [3] 746-49 (1990).

${ }^{i} \mathrm{C}$. R. Gazzara and D. R. Messier, "Determination of Phase Content of $\mathrm{Si}_{3} \mathrm{~N}_{4}$ by X-ray Diffraction Analysis," Am. Ceram. Soc. Bull., 56 [9] 777-80 (1977).

${ }^{15}$ D. D. Lee, S.-J. L. Kang, and D. N. Yoon, "Mechanism of Grain Growth and $\alpha-\beta^{\prime}$ Transformation During Liquid-Phase Sintering of $\beta^{\prime}$-SiAlON," $J$. Am Ceram. Soc, 71 [9] 803-806 (1988).
${ }^{16} \mathrm{I}-\mathrm{W}$. Chen and S. L. Hwang, "Shear Thickening Creep-Superplastic SiAlONs," J. Am. Ceram Soc., 75 [5] 1073-79 (1992).

${ }^{17} \mathrm{I}-\mathrm{W}$. Chen and S. L. Hwang, "Superplastic SiAlON-A Bird"s Eye View of Silicon Nitride Ceramics"; pp. 209-22 in Materials Research Society Symposia Proceedings, Vol. 287, Silicon Nitride Ceramics-Scientific and Technological Advances. Edited by I-W. Chen, P. F. Becher, M. Mitomo, G. Petzow and T. S. Yen. Materials Research Society, Pittsburgh, PA, 1993.

${ }^{18}$ S.-L. Hwang and I-W. Chen, "Nucleation and Growth of $\alpha$ '-SiAION on $\alpha$-Si ${ }_{3}$," J. Am. Ceram. Soc., 77 17| 1711-18 (1994); "Nucleation and Growth of $\beta^{\prime}$-SiAlON," ibid., 77 [7] 1719-28 (1994).

"I-W. Chen, "Superplastic Flow of Two-Phased Alloys"; pp. 5.1-5.20 in Superplasticity. Edited by B. Baudelet and M. Suery. Editions du CNRS, Paris, France, 1985

${ }^{20}$ T. Rouxel, J. L. Besson, C. Gault, and P. Goursat, "Elastic Properties and Crystallization in SiYAION Glasses and Ceramics"; in Proceedings of the $7 s t$ European Ceramics Symposium. Euro Ceramics, Vol. 3, Engineering Ceramics. Edited by G. de With, R. A. Terpstra, and R. Metselaar. Elsevier Applied Science, London, U.K., 1990.

${ }^{2 \prime}$ R. A. W. Drew, S. Hampshire, and K. H. Jack, "The Preparation and Properties of Oxynitride Glasses"; pp. 323-30 in Progress in Nitrogen Ceramics. Martinus Nijhoff Publishers, Boston. MA, 1983.

${ }^{22}$ C. Z. Cao and R. Metselaar, " $\alpha$ '-SiAlON Ceramics: A Review," Chem Mater, 3, 242-52 (1991).

${ }^{23} \mathrm{C}$. K. Yoon and I-W. Chen, "Superplastic Flow of Two-Phase Ceramics Containing Rigid Inclusions-Zirconia/Mullite Composites," I. Am. Ceram. Soc, $73[6]$ 1555-65 (1990).

${ }^{24}$ P. F. Becher, "Microstructural Design of Toughened Ceramics," J.Am. Ceram. Soc., 74 [2] 255-69 (1991). 